\title{
High-power table-top white-light few-cycle laser generator
}

\author{
Walid Tawfik \\ Department of Physics and Astronomy, College of Science, King Saud University, \\ Riyadh 11451, Saudi Arabia \\ Department of Environmental Applications, National Institute of Laser NILES, \\ Cairo University, Cairo, Egypt
}

Received: 26.05 .2015

\begin{abstract}
We have achieved experimentally a generation of white-light few-cycle femtosecond laser pulses, using a neon-filled hollow-core fibre. The pulses observed by us are as short as $6.22 \mathrm{fs}$ at the repetition rate of $1 \mathrm{kHz}$, when the input is characterized by the parameters $2.5 \mathrm{~mJ}$ and $33 \mathrm{fs}$. Pulse compression has been achieved using a supercontinuum produced in a static neon-filled hollow fibre, while a pair of chirped mirrors have compensated the dispersion. Our technique allows for directly tuning the pulse duration via changing the gas pressure, while maintaining near-transform-limited pulses with constant output energies and thus reducing the complications introduced by the chirped pulses. Using the measurements of the optical transmission of the fibre as a function of the gas pressure, we have testified a high enough throughput exceeding 60\%. This demonstrates the successful compression that yields few-cycle femtosecond-long pulses, with a wide spectral bandwidth. The technique can be used when simultaneously exciting different states in complex molecules.
\end{abstract}

Keywords: ultrafast lasers, hollow fibres, femtosecond pulses, few-cycle light pulses

PACS: $78.47 . j \mathrm{jj}$

UDC: 535.37

\section{Introduction}

Short laser pulses induced in plasma have been a precursor for many significant applications, including table-top soft X-ray lasers [1, 2], laser-induced plasma spectroscopy [3], and laserinduced high-order harmonics generation. These have become an important tool in generating coherent attosecond laser pulses in the X-UV range [4-6]. In common, the strength of the laserplasma interactions relies on the intensity of driving radiation. Advanced power densities have recently been achieved, beginning a battle for ever shorter laser pulses as an exclusive means for time-resolved measurements of various ultrashort processes [7].

A decrease in the laser-pulse durations down to a few optical cycles, while maintaining high energies, is to provide very high electric fields and accelerate electrons up to keV-range energies, which is sufficient to quench the atomic Coulomb potential and yield ultrafast (attosecond-range duration) coherent pulses in the UV and even X-ray ranges [8,9]. These features allow generating ultrafast molecular reactions that comprise electronic excitation and ionization dynamics. Recently, a few-cycle (4 fs) pulse located at $720 \mathrm{~nm}$ has been used to control spatial localization of the excited electronic states in a $\mathrm{C}_{60}$ fullerene [10]. Although nowadays it is easy to generate and amplify the moderately ultrashort ( $\sim 20 \mathrm{fs})$ pulses up to the Joule levels, the amplification of shorter pulses even to $\mathrm{mJ}$ level represents a challenging task [11]. In theory, this can be achieved

Ukr. J. Phys. Opt. 2015, Volume 16, Issue 3 
while starting with the picosecond or femtosecond regions to be compressed further down to a few-cycle regime. The latter can be maintained through the two types of pulse compression, a linear pulse and nonlinear pulse ones [12].

The linear pulse compression works as follows: once the laser pulses are chirped, their period can be shrunk by eliminating this chirp, i.e. by broadening the spectral phase. The latter can be implemented using a chromatic dispersion that appears when the pulses pass through a dispersive optical element like an optical fibre, a pair of diffraction gratings or prisms, or chirped mirrors $[13,14]$. Then the shortest feasible pulse duration is limited by the optical bandwidth of the pulses, which cannot be altered by a dispersive compression. In the case of the nonlinear pulse compression, the optical bandwidth is typically increased by a supercontinuum which can be generated using a self-phase modulation in some nonlinear medium [15]. Consequently, the durations of the resulting chirped pulses from the self-phase modulation can be strongly reduced by the linear compression [14].

White-light generation via the self-phase modulation has been reported for the first time by Alfano et al. [16] who have obtained spectral broadening for the picosecond Nd:YAG laser pulses (532 $\mathrm{nm}$ and $5 \mathrm{~mJ}$ ) passing through a borosilicate glass. Actually, it is a real challenge to employ the effective dispersion compensation and return an isolated ultrashort optical pulse using the supercontinuum generation [17]. In the recent years, significant progress has been made in the generation of supercontinuum in the VIS-NIR spectral ranges, using hollow microstructured fibres or two gas-filled hollow fibres in a cascading configuration [18].

Recently, high-power laser schemes mostly employ Ti:sapphire amplifiers and many terawatt-class laser schemes have been developed [19, 20]. However, these very complex systems suffer from wavefront distortions and thermal lensing appearing due to thermal load imposed on the amplifiers by intense short pulses. Cryogenic cooling of Ti:sapphire crystals has been introduced to compensate these heat effects [21]. Similar to laser cooling of trapped ions, here the ground-state cooling of an optomechanical system represents in fact a radiation-pressure cooling in the resolved-sideband limit, where the cavity-photon lifetime surpasses the mechanical oscillation time [22-24].

\section{High-energy chirped pulse amplification}

A chirped-pulse amplification (CPA) is an alternative to the complex Ti:sapphire amplification. It is very favourable for the generation of high-power few-cycle laser pulses [25]. For instance, the CPA of the ultrashort laser pulses produced by solid-state lasers has allowed creating optical pulses in the GW-TW range, with still brighter promises [26-28]. The CPA systems are now very common in the ultrafast spectroscopy, nonlinear optics, and the high-field laser science [29, 30].

To seed the CPA, low-energy ultrashort pulses are needed to be temporally broadened in a dispersive pulse stretcher in order to prevent damaging the gain medium during the amplification process. A group-delay dispersion of the opposite sign is introduced to remove the chirp of the amplified pulses and restore the pulse duration close to that of the input pulse. The conventional CPA systems rely on very complex and alignment-sensitive systems of prisms and gratings [31, 32] for the pulse stretching and recompression. These in fact control a spatio-temporal quality and production efficiency for the pulses being amplified. When the prisms or diffraction gratings are used, their angular dispersion presents a favourite wavelength-dependent delay. On the other hand, the system is very sensitive to the alignment of its components, which can introduce severe difficulties in practical operation of the CPA systems. This is because any small thermal or 
mechanical fluctuations cause tiny deviations from the optimal alignments of the grating or the prism, which induce an angular chirp and a pulse-front distortion. The result is decay of the pulse profile at the focus on both temporal and spatial scales [33]. Furthermore, a fairly large amount of unrecompensed higher-order dispersion needs an extra-dispersion control such as multilayer dispersive mirrors [34, 35] or hybrid (grating-prism-material) stretcher-compressor systems [36], whenever one deals with bandwidth-limited pulses in the broadband amplifiers working in the $10 \mathrm{fs}$ regime [37].

Here we report a novel technique for generating few-cycle femtosecond light pulses, using a gas-filled hollow-core fibre. Using the experimental configuration suggested in this work, $6.22 \mathrm{fs}$ output light pulses have been obtained with the energies of up to $0.6 \mathrm{~mJ}$, using a $32 \mathrm{fs}$ laser with the $2.5 \mathrm{~mJ}$ energy and the $1 \mathrm{kHz}$ repetition rate. The pulse compression is attained by the supercontinuum created in the gas-filled hollow fibre, whereas the dispersion is compensated via the chirped mirrors. This technique allows for preserving near-transform-limited pulses with fixed output energies, thus reducing some problems imposed by the chirped pulses.

\section{A few-cycle white-light laser generator setup}

A scheme of our laser system with a detailed optical layout is shown in Fig. 1. In this system, the amplification is made by a $1 \mathrm{kHz}$ regenerative CPA amplifier that produces $32 \mathrm{fs}, 2.5 \mathrm{~mJ}$ pulses at $800 \mathrm{~nm}$. A $15 \mathrm{fs}$ mode-locked Ti:sapphire seed oscillator $(400 \mathrm{~mW}, 75 \mathrm{MHz}$, and $800 \mathrm{~nm}$ ) generates femtosecond laser pulses in the $\mathrm{TEM}_{00}$ mode. The basic oscillator setup consists of pump beam mirrors PM1 and PM2, folded cavity mirrors, a pump beam focusing lens, a pair of concave spherical mirrors aligned with the Ti:sapphire laser rod, an output coupler, coated metal mirrors $\mathrm{Rm} 1$ and $\mathrm{Rm} 2$, a set of prisms used for dispersion compensation, and a slit that serves as a spectral tuning element. The oscillator can be tuned from $780 \mathrm{~nm}$ to $820 \mathrm{~nm}$. The seed oscillator is pumped by a $4 \mathrm{~W}, 532 \mathrm{~nm}$ green diode-pumped $\mathrm{CW}$ solid-state DPSS laser Opus (Laser Quantum).

The seed pulses are stretched in the temporal domain by means of a stretcher. The stretcher is employed according to a standard double-path scheme, with a single diffraction grating SG and a telescope formed by a flat mirror SM4 and a spherical mirror SS with broadband dielectric coatings. After passing through a Faraday isolator (FI) that changes the polarization from horizontal to vertical, the stretched pulses are injected into a regenerative amplifier RA with the aid of a first Pockels cell RPC1. After a necessary number of resonator round trips, the energy of the laser pulse reaches its maximum value higher than $3 \mathrm{~mJ}$. The amplified laser pulses are released from the RA resonator by a second Pockels cell RPC2. This is done by applying short, bell-shaped high-voltage pulses to the cell RPC2, which acts as a quarter-wave plate. The amplifier RA is pumped with a pulsed green laser (a diode-pumped Nd:YLF Q-switched laser with the wavelength of $527 \mathrm{~nm}$, the energy of $20 \mathrm{~mJ}$, the duration of $170 \mathrm{~ns}$ and the repetition rate of $1 \mathrm{KHz}$ ), using a vertically polarized laser model DM20-527 (Photonics Industries).

After passing the amplifier RA, the laser pulse is sent to a gate subsystem (a further pulse picker) that consists of two crossed polarizers and a third Pockels cell placed in between. The pulse picker is used to control the laser output with an external gate signal and to enhance the contrast. Finally, the pulse is compressed back to the femtosecond regime via a compressor. To prevent any possible damage of the optical elements of the compressor, we expand the beam using a telescope composed of the mirrors TT1 and TT2. The compressor includes an input mirror CM1, a diffraction grating CG, a mirror assembly CM2 and CM3, a 'roof' mirror assembly CR, and an 
output mirror CM4. The laser beam strikes the grating four times inside the compressor. Behind the compressor, the laser pulses acquire the duration $32 \mathrm{fs}$ at the $2.5 \mathrm{~mJ}$ energy and the $1 \mathrm{kHz}$ repetition.

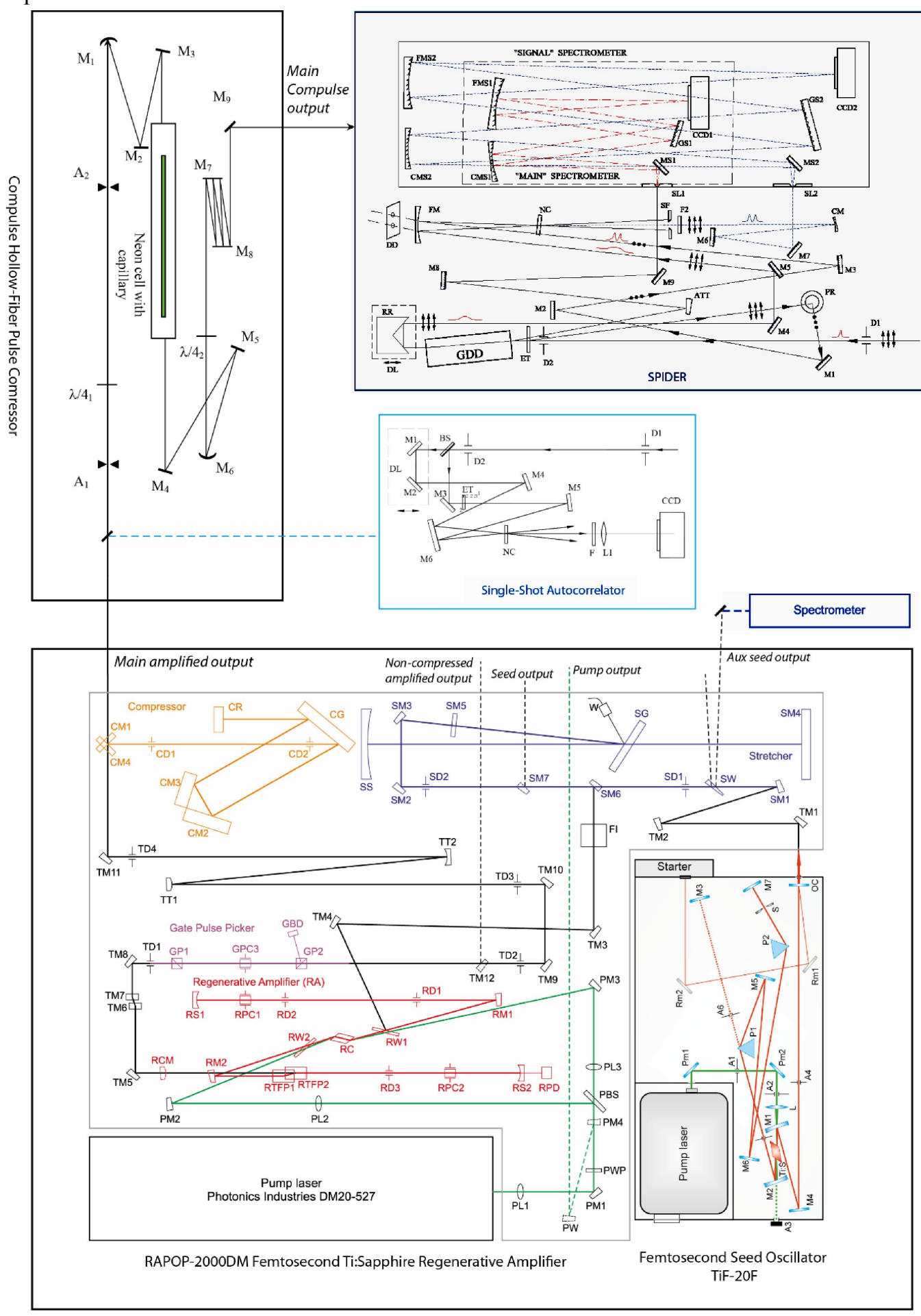

Fig. 1. Optical layout of our few-cycle white-light generator. 
The resulting amplified pulse is directed towards a final stage which produces the few-cycle pulse regime. We conventionally call this stage as a Compulse compressor. The Compulse is composed of a one-metre hollow fibre filled with a neon gas, which is followed by a multilayered chirped-mirror compressor. Using a concave mirror M1 with $f=1.2 \mathrm{~m}$, the laser radiation is focused onto the fused silica fibre with the inner diameter of $250 \mu \mathrm{m}$. The spectrum of the pulse is broadened via the self-phase modulation in the neon gas under the controlled pressure up to $2.5 \mathrm{~atm}$. Finally, the output beam is collimated by a mirror M6 and then compressed between two chirped mirrors M7 and M8, thus reaching the few-cycle regime.

\section{Results and discussion}

The output beam characteristics depend on many parameters, including the nonlinear phase shift due to the supercontinuum occurring in the neon gas, the chirped-mirror compressor and the beam properties of both the seed and CPA amplifiers. The throughput efficiency of the optical fibre and the beam bandwidth affect the output properties, too.

The autocorrelation measured for the case of optimized seed-beam oscillator is shown in Fig. 2. These measurements have been taken using a single-shot autocorrelator, as shown in Fig. 1 [38]. The mode-locked pulse duration is optimized at $18 \mathrm{fs}$ for the central wavelength of $795 \mathrm{~nm}$ and the bandwidth of $52 \mathrm{~nm}$. The oscillator wavelength can be tuned in the region $750-850 \mathrm{~nm}$ with the help of a couple of prisms combined with a variable optical slit. These elements provide a region in the cavity where all the spectral components of the Ti:sapphire emission are spatially spread. While the oscillator wavelength can be tuned by changing the position of the slit in the horizontal plane, the bandwidth of the output can be changed by varying the width of that slit.

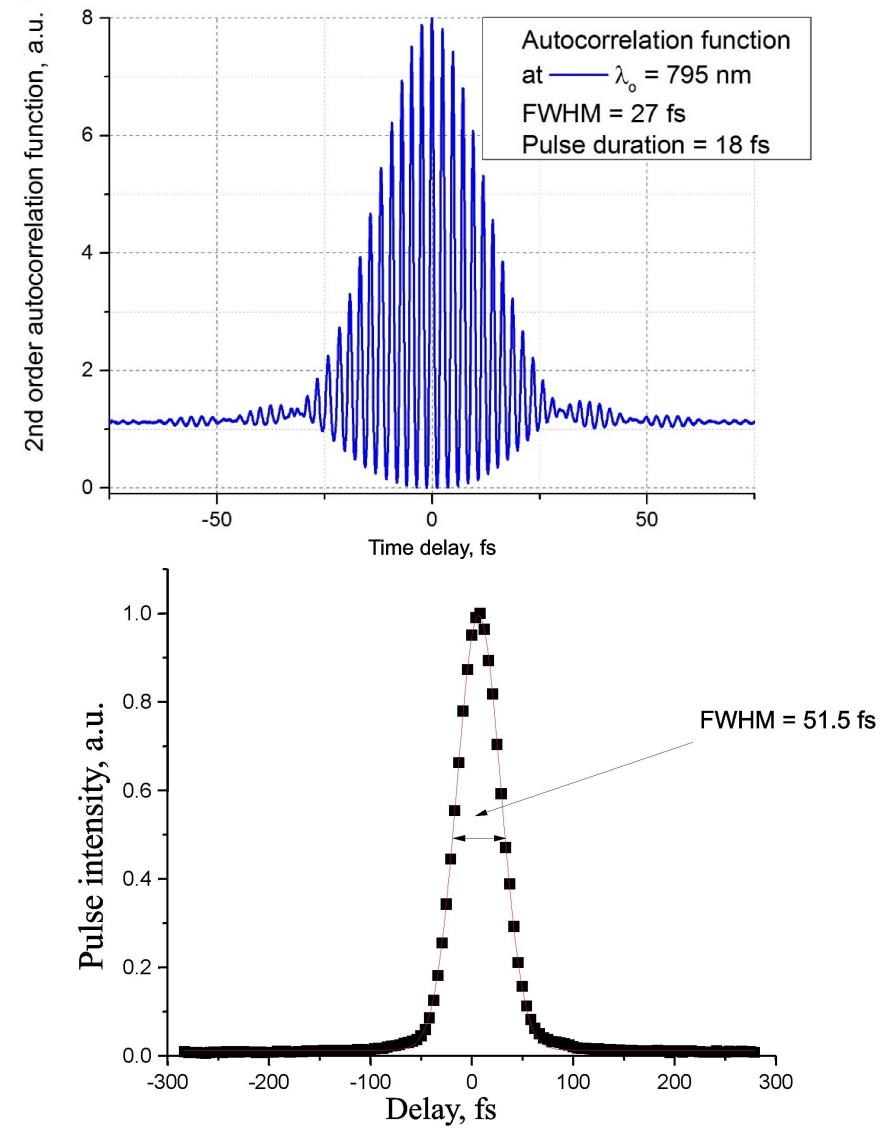

Fig. 2. Autocorrelation function for the Ti:sapphire oscillator, as measured at $795 \mathrm{~nm}$ and the bandwidth $52 \mathrm{~nm}$.

Fig. 3. Illustration of estimations of the pulse width (in $\operatorname{sech}^{2}$ ) following from the FWHM of the autocorrelation signal. The result is equal to $33.4 \mathrm{fs}$.

Ukr. J. Phys. Opt. 2015, Volume 16, Issue 3 
The amplified femtosecond pulse observed after the CPA is illustrated in Fig. 3. Given the estimation for the pulse width (in $\operatorname{sech}^{2}$ ), the pulse duration is approximately 0.65 from the width of the autocorrelation signal (the FWHM). Since the Gaussian curve fitting of the experimental autocorrelation has resulted in the FWHM equal to $51.5 \mathrm{fs}$, the pulse width is estimated as $33.4 \mathrm{fs}$.

The bandwidth of the amplified pulses has been measured with a spectrometer (see Fig. 4). The bandwidth of the amplified signal is found to be $25.8 \mathrm{~nm}$ at the central wavelength $\left(\lambda_{0}=\right.$ $797.28 \mathrm{~nm}$ ) and for the pulse duration of $33.4 \mathrm{fs}$. After the CPA, the transverse beam profile resembles a standard Gaussian $\mathrm{TEM}_{00}$ distribution. The image of the amplified signal-beam profile taken using a CCD camera is shown in Fig. 5. At this stage, the output pulse energy reaches the value $2.5 \mathrm{~mJ} /$ pulse for both the single pulse and the $1 \mathrm{KHz}$ modes.

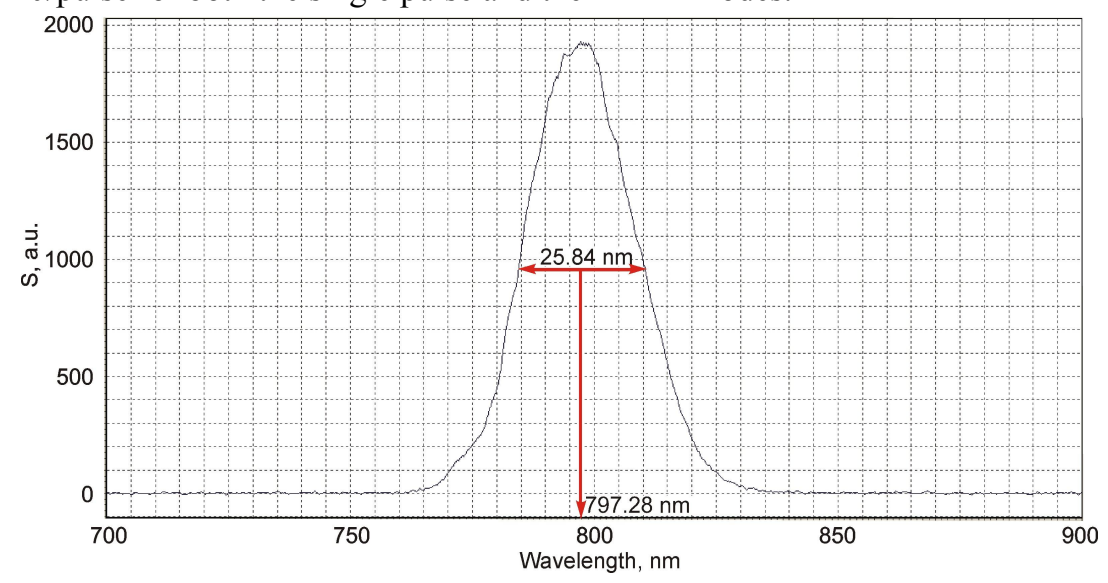

Fig. 4. Illustration of estimations of the bandwidth of the amplified signal $\left(\lambda_{0}=797.28 \mathrm{~nm}\right.$ and the pulse duration $33.4 \mathrm{fs}$ ). The result is equal to $25.8 \mathrm{~nm}$.

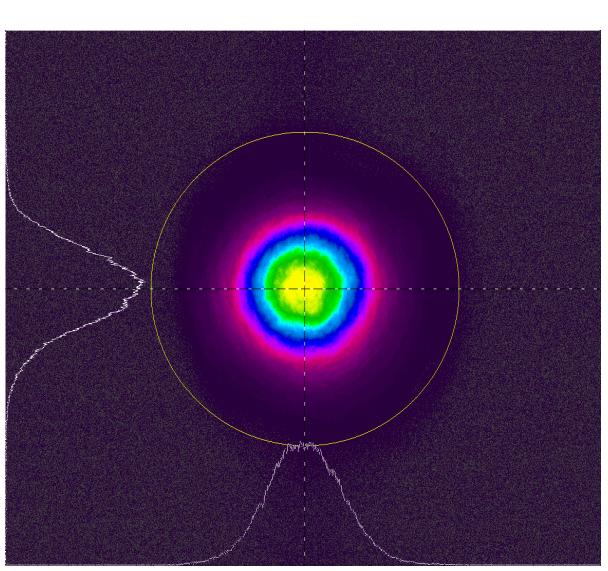

Fig. 5. Beam profile images recorded for the $2.5 \mathrm{~mJ}$ output beam emergent from the CPA power amplifier, which show the Gaussian transverse distribution $\mathrm{TEM}_{00}$.

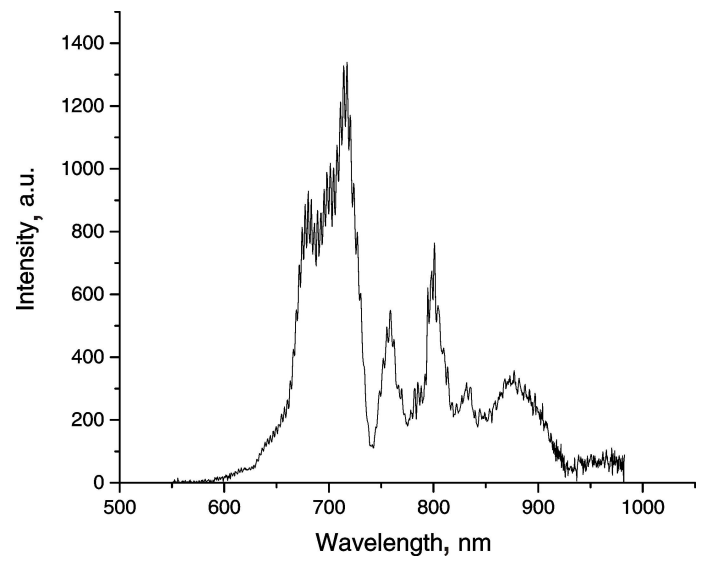

Fig. 6. Illustration of spectral broadening of the output beam $(\sim 350 \mathrm{~nm})$.

In fact, the very narrow bandwidth typical for the laser gain media forbids creating the fewcycle pulses directly from the CPA system. To overcome this fundamental restriction, the external spectral broadening based on the hollow fibre and the subsequent pulse compression are utilized, using the Compulse stage (see Fig. 6). By optimizing a metre-long hollow fibre at the pressure $2.5 \mathrm{~atm}$, we have reduced the input $2.5 \mathrm{~mJ}$ pulses to $1.5 \mathrm{~mJ}$ behind the fibre, which indicates a high 


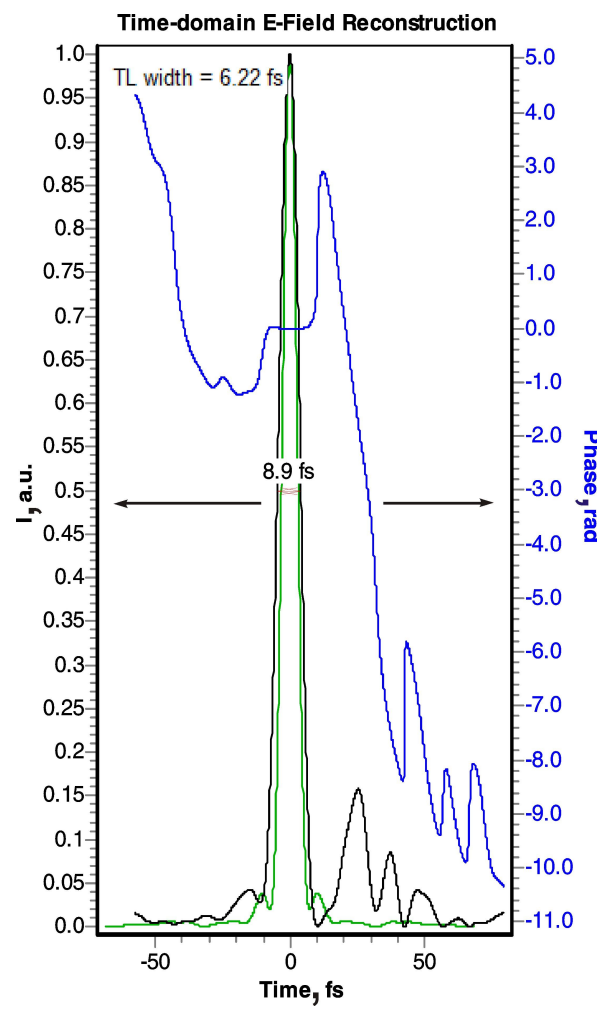

Fig. 7. Temporal profile of the compressed output pulse (black curve) and temporal phase (blue curve) of the compressed output pulses measured using a spectral phase interferometry for direct electric-field reconstruction. After the compression, the transform-limited output pulse (green curve) is characterized with $6.22 \mathrm{fs}$. efficiency $(\sim 60 \%)$ for our system. To characterize the compressed output pulse, we have used a spectral phase interferometry for directly reconstructing the electric field [39] (see Fig. 1). The spectral phase measured for the pulses with the FWHM duration $8.9 \mathrm{fs}$ is within $6 \%$ of the Fourier limit (6.22 fs). The peak power of the pulses is then $\sim 0.1 \mathrm{TW}$. The temporal pulse structure and its phase are displayed in Fig. 7. The pulse-to-pulse output power fluctuations measured by us are about $2.5 \%$ for the final output (i.e., after passing the Compulse stage), and 1\% after the CPA.

\section{Conclusion}

Summing up, we have demonstrated a production of $6.22 \mathrm{fs}$ pulses having ultrawide spectral bandwidths (600-950 nm), with the corresponding peak powers ranging towards the TW frontiers. Our system is compact, table-top and robust, with the power fluctuations not exceeding 3\%. The wide spectral-band pulses observed by us can be used to study transient absorption in the complex molecules for different simultaneous transitions. Using the supercontinuum with spectrally wider pulses, the compression down to one femtosecond and, probably, even into the attosecond regime can become possible in the near future, using the ultraviolet and X-ray pulses.

\section{Acknowledgement}

This work has been funded by the National Plan for the Science, Technology and Innovation (MAARIFAH), King Abdulaziz City for Science and Technology, Kingdom of Saudi Arabia (the Award Number 12-ELE2628-02).

\section{References}

1. Rocca J J, Shlyaptsev V, Tomasel F G, Cortázar O D, Hartshorn D and Chilla J L A, 1994. Demonstration of a discharge pumped table-top soft-X-ray laser. Phys. Rev. Lett. 73: 2192.

2. Rocca J J, Shlyaptsev V N, Tomasel F G, Cortázar O D, Hartshorn H and Chilla J L A, 1995. Demonstration of a Discharge Pumped Table-Top Soft-X-Ray Laser. Phys. Rev. Lett. 75: 1236.

3. Walid Tawfik, Aslam Farooq W and Alahmed Z A, 2014. Damage profile of HDPE polymer using laser-induced plasma. J. Opt. Soc. Korea. 18: 50-54.

4. Agostini P and DiMauro L, 2004. The physics of attosecond light pulses. Rep. Prog. Phys. 67: 813-855.

5. Krausz F and Ivanov M, 2009. Attosecond physics. Rev. Mod. Phys. 81: 163-234.

6. Feng L Q and Chu T S, 2012. Nuclear signatures on the molecular harmonic emission and the attosecond pulse generation. J. Chem. Phys. 136: 054102

7. Cairns R A, Bingham R, Jaroszynski D A and Baron M. Laser-plasma interactions (Taylor \& 
Francis, 2009).

8. Hentschel M, Kienberger R, Spielmann C, Reider G A, Milosevic N, Brabec T, Corkum P B. Heinzmann U, Drescher D, and Krausz F, 2001. Attosecond metrology. Nature. 414: 509513.

9. Helml W, Maier A R, Schweinberger W, Grguraš I, Radcliffe P, Doumy G, Roedig C, Gagnon J, Messerschmidt M, Schorb S, Bostedt C, Grüner F, DiMauro L F, Cubaynes D, Bozek J D, Tschentscher Th, Costello J T, Meyer M, Coffee R, Düsterer S, Cavalieri A L and Kienberger R, 2014. Measuring the temporal structure of few-femtosecond free-electron laser X-ray pulses directly in the time domain. Nature Photonics. 8: 950-957.

10. Li H, Mignolet B, Wachter G, Skruszewicz S, Zherebtsov S, Süßmann F, Kessel A, Trushin SA, Kling Nora G, Kübel M, Ahn B, Kim D, Ben-Itzhak I, Cocke CL, Fennel T, Tiggesbäumker J, Meiwes-Broer K-H, Lemell C, Burgdörfer J, Levine RD, Remacle F and Kling MF, 2015. Coherent electronic wave packet motion in $\mathrm{C}_{60}$ controlled by the waveform and polarization of few-cycle laser fields. Phys. Rev. Lett. 114: 123004.

11. Ishii N, Turi L, Yakovlev V S, Fuji T, Krausz F, Baltuska A, Butkus R, Veitas G, Smilgevicius V, Danielius R and Piskarskas A, 2005. Multimillijoule chirped parametric amplification of few-cycle pulses. Opt. Lett. 30: 567-569.

12. Shank C V, Fork R L, Yen R, Stolen R H and Tomlinson W J, 1982. Compression of femtosecond optical pulses. Appl. Phys. Lett. 40: 761-762.

13. Martinez O E, Gordon J P and Fork R L, 1984. Negative group-velocity dispersion using refraction. J. Opt. Soc. Amer. A. 1: 1003-1006.

14. Fork R L, Martinez O E and Gordon J P, 1984. Negative dispersion using pairs of prisms. Opt. Lett. 9: 150-152.

15. Tomlinson W J, Stolen R H and Shank C V, 1984. Compression of optical pulses chirped by self-phase modulation in fibers. J. Opt. Soc. Amer. B. 1: 139-149.

16. Alfano RR, Li Q, Jimbo T, Manassah J and Ho P, 1986. Induced spectral broadening of a weak picosecond pulse in glass produced by an intense ps pulse. Opt. Lett. 11: 626-628.

17. Schenkel B, Biegert J, Keller U, Vozzi C, Nisoli M, Sansone G, Stagira S, De Silvestri S and Svelto O, 2003. Generation of 3.8-fs pulses from adaptive compression of a cascaded hollow fiber supercontinuum. Opt. Lett. 28: 1987-1989.

18. Nisoli M, Sansone G, Stagira S, De Silvestri S, Svelto O and Vozzi C, 2002. Ultra-broadband continuum generation by hollow-fiber cascading. Appl. Phys. B. 75: 601-604.

19. Ito S, Ishikawa H, Miura T, Takasago K, Endo A, Torizuka K, 2003. Seven-terawatt Ti:sapphire laser system operating at $50 \mathrm{~Hz}$ with high beam quality for laser Compton femtosecond X-ray generation. Appl. Phys. B. 76: 497-503.

20. Seres J, Muller A, Seres E, O'Keeffe K, Lenner M, Herzog R F, Kaplan D, Spielmann Ch and Krausz F, 2003. Sub-10-fs terawatt-scale Ti:sapphire laser system. Opt. Lett. 28: 1832-1834.

21. Young-Shin Park and Hailin Wang, 2009. Resolved-sideband and cryogenic cooling of an optomechanical resonator. Nature Physics. 5: 489-493.

22. Wilson-Rae I, Nooshi N, Zwerger W and Kippenberg T J, 2007. Theory of ground state cooling of a mechanical oscillator using dynamical back action. Phys. Rev. Lett. 99: 093901.

23. Marquardt F, Chen JP, Clerk A A and Girvin S M, 2007. Quantum theory of cavity-assisted sideband cooling of mechanical motion. Phys. Rev. Lett. 99: 093902.

24. Schliesser A, Riviere R, Anetsberger G, Arcizet O and Kippenberg T J, 2008. Resolvedsideband cooling of a micromechanical oscillator. Nature Phys. 4: 415-419.

25. Pervak V, Ahmad I, Trushin S A, Major Z, Apolonski A, Karsch S and Krausz F, 2009. Chirped-pulse amplification of laser pulses with dispersive mirrors. Opt. Express. 17: 1920419212. 
26. Mourou G A, Tajima T and Bulanov S V, 2006. Optics in the relativistic regime. Rev. Mod. Phys. 78: 309- 371 .

27. Perry M D and Mourou G, 1994. Terawatt to petawatt subpicosecond lasers. Science. 264: 917-924.

28. Gerstner E, 2007. Laser physics: extreme light. Nature 446: 16-18.

29. Krausz F and Ivanov M, 2009. Attosecond physics. Rev. Mod. Phys. 81: 163-234.

30. Brabec $\mathrm{T}$ and Krausz F, 2000. Intense few-cycle laser fields: frontiers of nonlinear optics. Rev. Mod. Phys. 72: 545-591.

31. Treacy E B, 1969. Optical pulse compression with diffraction gratings. IEEE J. Quantum Electron. 5: 454-458.

32. Pessot M, Maine P and Mourou G, 1987. 1000 Times expansion compression of optical pulses for chirped pulse amplification. Opt. Commun. 62: 419-421

33. Cheng Z, Krausz F and Spielmann C, 2002. Compression of $2 \mathrm{~mJ}$ kilohertz laser pulses to 17.5 fs by pairing doubleprism compressor: analysis and performance. Opt. Commun. 201: 145-155.

34. Pretzler G, Kasper A and Witte K J, 2000. Angular chirp and tilted light pulses in CPA lasers. Appl. Phys. B. 70: 1-9.

35. Cavalieri A L, Goulielmakis E, Horvath B, Helml W, Schultze M, Fieß M, Pervak V, Veisz L, Yakovlev V S, Uiberacker M, Apolonski A, Krausz F and Kienberger R, 2007. Intense 1.5cycle near infrared laser waveforms and their use for the generation of ultra-broadband soft-Xray harmonic continua. New J. Phys. 9: 242.

36. Tavella F, Nomura Y, Veisz L, Pervak V, Marcinkevičius A, and Krausz F, 2007. Dispersion management for a sub-10-fs, $10 \mathrm{TW}$ optical parametric chirped-pulse amplifier. Opt. Lett. 32: 2227-2229.

37. Chuzavkov Yu L, Orlov S N, Polivanov Yu N, Schelev Mikhail Y, Smirnov A V, Smirnov V V, Vorobiev N S, 1999. Single-shot autocorrelator. Proc. SPIE. 3516: 743 (23 ${ }^{\text {rd }}$ International Congress on High-Speed Photography and Photonics).

38. Schenkel B, Biegert J, Keller U, Vozzi C, Nisoli M, Sansone G, Stagira S, De Silvestri S and Svelto O, 2003. Generation of 3.8-fs pulses from adaptive compression of a cascaded hollow fiber supercontinuum. Opt. Lett. 28: 1987-1989.

39. Gallmann L, Steinmeyer G, Sutter D H, Rupp T, Iaconis C, Walmsley I A and Keller U, 2001. Spatially resolved amplitude and phase characterization of femtosecond optical pulses. Opt. Lett. 26: 96-98.

Walid Tawfik. 2015. High-power table-top white-light few-cycle laser generator. Ukr.J.Phys.Opt. 16: $111-119$.

Анотація. У цій роботі експериментально отримано генерацію “білих” фемтосекундних лазерних імпульсів тривалістю в кількох періодів, використовуючи пустотіле волокно, наповнене неоном. Тривалість спостережуваних імпульсів сягала 6.22 фм за частоти повторення 1 кГи, якщо використовувати вхідні імпульси із 2.5 мДж $і 33$ фс. Стискання імпульсу суперконтинуума отримано в статичних, заповнених неоном пустотілих волокнах, а пара дзеркал з лінійною частотною модуляцією забезпечувала компенсацію дисперсіі. Запропонований метод дає змогу безпосередньо змінювати тривалість імпульсу тиском газу при збереженні параметрів імпульсу, тим самим послаблюючи труднощі, пов'язані з модульованими імпульсами. Вимірюване пропускання волокна як функція тиску газу перевищувало 60\%. Спектральна фаза суперконтинууму виявилась стабільною впродовж кількох годин. Це дало змогу стиснути імпульси аж до фемтосекунд, щяо складає кілька періодів, із широкою спектральною смугою. Метод можна використовувати для одночасного збудження різних рівнів у складних молекулах.

Ukr. J. Phys. Opt. 2015, Volume 16, Issue 3 